\title{
Validity and reliability of the Korean version of the Wisconsin Smoking Withdrawal Scale
}

\author{
Hyonsoo Joo ${ }^{1}$, Hyeon Hui Kang ${ }^{2,{ }^{*}}$, Hwa Sik Moon ${ }^{2,{ }^{\star}}$, and Sang Haak Lee ${ }^{2,{ }^{\star}}$
}

${ }^{1}$ Department of Internal Medicine, Uijeongbu St. Mary's Hospital, College of Medicine, The Catholic University of Korea, Uijeongbu; ${ }^{2}$ Department of Internal Medicine, St. Paul's Hospital, College of Medicine, The Catholic University of Korea, Seoul, Korea

Received: October 2, 2018

Revised : May 5, 2019

Accepted: July 3, 2019

\section{Correspondence to}

Sang Haak Lee, M.D.

Department of Internal

Medicine, Eunpyeong St. Mary's

Hospital, College of Medicine,

The Catholic University of Korea, 1021 Tongil-ro, Eunpyeong-gu,

Seoul 03312, Korea

Tel: +82-2-2030-2605

Fax: +82-2-2030-3761

E-mail:agmante@gmail.com

*Current affiliation: Department of Internal Medicine, Eunpyeong St. Mary's Hospital, College of Medicine, The Catholic

University of Korea, Seoul, Korea
Background/Aims: This study evaluated the validity and reliability of the Korean version of the Wisconsin Smoking Withdrawal Scale (WSWS-K) for use in clinical practice and research on Korean smokers.

Methods: The Wisconsin Smoking Withdrawal Scale was translated into Korean and then back-translated into English. The authors reviewed the translation and back-translation and approved the final questionnaire draft. The validity and reliability of the WSWS-K were evaluated based on data collected from 300 participants. Construct validity was evaluated with a confirmatory factor analysis. Criterion-related validity was assessed by examining the relationships between the subscales of the WSWS-K and the matched items of the Korean version of the Minnesota Nicotine Withdrawal Scale (MNWS-K).

Results: The participants were predominantly male (93.6\%) and the mean age was $59.23 \pm 15.19$ years. The confirmatory factor analysis revealed that fit indices (namely, the goodness-of-fit index, adjusted goodness-of-fit index, comparative fit index, and the normed fit index) exceeded or approached o.9. Cronbach's alpha for the entire scale was 0.87 . The total score of the WSWS-K had a statistically significant positive correlation with that of the MNWS-K (Pearson's correlation coefficient, $0.768 ; p<0.01$ ). Additionally, we performed linear regression between the WSWS-K and MNWS-K scores after adjusting for age, gender, comorbidity, and smoking history. After this adjustment, the $p$ value of the WSWS-K was $<0.001$.

Conclusions: The WSWS-K had satisfactory validity and reliability. The WSWS-K can be used with acceptable validity and reliability in research and clinical evaluation of Korean smokers.

Keywords: Smoking cessation; Validity and reliability; Translations

\section{INTRODUCTION}

Cigarette smoking is the leading cause of preventable disease and death in the United States, accounting for more than 400,000 deaths every year [1]. Smoking-related illnesses in the United States cost more than $\$ 300$ billion each year, including nearly $\$ 170$ billion for direct medical care for adults and more than $\$ 156$ billion in lost productivity [1]. In 2015, approximately 36.5 million adults in the United States smoked cigarettes and more than 16 million lived with a smoking-related disease [2]. In Korea, the prevalence of smoking is quite high: the 2015 Korean National Health and Nutrition Examination Survey reported an overall smoking rate of $22.6 \%$, with rates of $39.3 \%$ and $5.5 \%$ among men and women over the age of 19 , respectively [3]. 
People who smoke may have their lifespan shortened by more than a decade compared with those who have never smoked [4]. Current smokers have significantly higher risk of major cause-specific mortality than never smokers, including all cardiovascular disease, sudden death, pulmonary disease, lung cancer, and smoking-related cancers including larynx, oral cavity, esophageal, pancreatic and stomach cancer. Compared with current smokers, the risk of death is significantly reduced among past smokers within 10 years of smoking cessation. By 20 years of smoking cessation, the risk is further decreased to the level of never smokers [5].

Nicotine is the substance in tobacco that causes addiction [6]. When quitting smoking, nicotine withdrawal syndrome occurs, because the body has developed a homeostatic response [7]. Withdrawal syndrome is characterized by symptoms such as irritability, frustration, anger, restlessness, insomnia, anxiety, depression, poor concentration, increased appetite, and intense cravings for nicotine $[7,8]$. Accurate and effective assessment of withdrawal symptoms is important, both theoretically and clinically.

The Minnesota Nicotine Withdrawal Scale (MNWS) was developed in 1986 [9] and later revised in 2005 by John Hughes. The MNWS is sensitive enough to measure 'difficulty concentration' and 'restlessness' but not 'depression' and 'disturbed sleep.' Furthermore, each withdrawal symptom is measured with a single item, which may lead to problems of decreased validity and reliability [10]. The Wisconsin Smoking Withdrawal Scale (WSWS) was developed to more reliably assess withdrawal symptoms. The WSWS contains 28 items and seven subscales, including anger, anxiety, concentration, cravings, hunger, sadness, and sleep [11]. Questions are answered on 5-point Likert-type scales ranging from 'strongly agree' to 'strongly disagree.' In the WSWS, each withdrawal symptom is measured with several items, thus increasing reliability.

Alpha coefficients for the subscales range from 0.75 to 0.93 . This self-reported outcome measure combines the strength of sensitivity to smoking withdrawal and is predictive of smoking cessation outcomes. Furthermore, the WSWS is sufficiently brief to be used in general clinical practice and research context [10-12]. Additionally, the psychometric properties of the WSWS have been tested in an internet cohort study $(n=4,644)$ [10].
Cronbach's alpha was 0.91, and the test-retest correlation coefficient over a 14-day period was 0.80 for the total score, thus supporting the validity of this scale [10].

The Korean version of the MNWS (MNWS-K) has been validated previously [13]. However, the MNWS has had its name changed to Minnesota Tobacco Withdrawal Scale to reflect that non-nicotine factors can influence the scores. The Minnesota Tobacco Withdrawal Scale includes eight well-validated items reflecting smoking withdrawal symptoms and seven other promising candidate items. This new scale has not yet been translated into Korean. Therefore, validation of tools for measuring smoking withdrawal symptoms in Korean smokers is required. The aim of this study was to validate the Korean version of the Wisconsin Smoking Withdrawal Scale (WSWS-K).

\section{METHODS}

\section{Translation of the WSWS}

After obtaining the original author's permission, stepwise processing was used to develop the WSWS-K: forward translation, backward translation for quality control, and pilot testing [14,15]. To ensure lexical equivalence, the translation of the original English version of the WSWS into the Korean language used the "back-translation" technique. First, the first and second authors, who are Korean-born and fluent in both English and Korean, translated the questionnaire into the Korean language. Back-translation was performed by two people. One was a professional translator, and the other was an American who lives in Korea and teaches the Korean language to non-native speakers at a university in Seoul. They independently and blindly translated the Korean version back into English; the back-translations were then compared to the original version. The authors reviewed the translation and back-translation and approved the final questionnaire draft (Supplementary Table 1). The Korean version was piloted with 20 physicians in our institute. When asked to comment on the clarity, comprehensibility, and readability of the Korean version, they reported that all items were clear and easy to understand. 


\section{Subjects and measurement}

Participants for the validation study were enrolled from among outpatients visiting St. Paul's Hospital between December 2016 and February 2017. Eligible participants were 15 years of age or older and were current smokers or had stopped smoking within the last year. Eligible participants had to be able to complete the scales independently and to provide informed consent after being informed of all the pertinent aspects of the questionnaire. We excluded participants who had a past or present history of depression or anxiety disorders according to the Diagnostic and Statistical Manual of Mental Disorders (DSM)-V, a past or present history of schizophrenia or other mental disorder, concomitant antidepressant, antianxiety, hypnotic or sedative medication, or current abuse of alcohol.

Participants were asked to complete the WSWS-K (Supplementary Table 2) based on the time since quitting smoking, and for criterion-related validity, they were asked to complete the MNWS-K [13] simultaneously. This study was approved by the Institutional Review Board/Ethics Committee of St. Paul's Hospital, the Catholic University of Korea (PC16QISIoo54). All patients gave written informed consent to participate in the study.

\section{Sample size determination}

The WSWS has 28 items. Therefore, a minimum of 280 participants were required to fulfill the requirement of at least 10 participants per item for factor analysis [16]. Taking the noneligibility of $15 \%$, the sample size was calculated to be at least 318 .

\section{Statistical methods}

Descriptive statistics and appropriate validity and reliability statistical tests were completed using SAS version 9.4 (SAS Institute, Inc., Cary, NC, USA) and R version 3.3.2 (R Foundation for Statistical Computing, Vienna, Austria). Data are expressed as mean \pm standard deviation (SD). To test construct validity, a confirmatory factor analysis (CFA) was performed. Welsch et al. [11] performed a CFA and compared the seven-factor model that guided the original scale development with alternative models including four-factor, one-factor, and second-order models. The result was a comparative fit index (CFI) of 0.91 for the seven-factor model, and the fit indices revealed that the seven-factor model provided superior fit compared to the other models [11]. Thus, we also performed a CFA for the seven-factor model. Multiple indicators and multiple causes (MIMIC) CFA was used to test the effects of covariates; gender, age, comorbidity and smoking history. We used a structural equation model to understand how the WSWS is predicted by these variables. Model verification in the CFA can be conducted on the basis of chi-squared tests, degrees of freedom, goodness-of-fit index (GFI), adjusted goodness-of-fit index (AGFI), CFI, normed fit index (NFI), root mean square residual (RMR), and root mean square error of approximation (RMSEA). The model fit is judged to be good if the GFI, AGFI, CFI, and NFI are 0.90 or greater and the RMR is 0.5 or less [17]. For the RMSEA, the model fit is judged to be good model if it is below 0.05 and desirable if it is below 0.10 [18-20].

The Pearson's correlation coefficient method was used to assess the relationship among subscales of WSWS-K and to assess criterion-related validity between the scores of the subscales of the WSWS and MNWS questionnaires. Simple linear regression was performed to examine the predictive validity of the two questionnaires. Cronbach's alpha was used to examine the internal consistency, and item-to-total correlation coefficients were also computed. The cut-off of the correlation of Cronbach's alpha was 0.70 .

\section{RESULTS}

\section{Participant characteristics}

A total of 318 participants were initially enrolled in this study. Of those 18 were excluded (five had a history of depression, six were taking sedatives, and seven had current abuse of alcohol). Finally, 300 participants were included in analysis. (Fig. 1); their baseline characteristics are summarized in Table 1. The participants were predominantly male (93.67\%) and the mean age was $59.23 \pm$ 15.19 years. The mean total cigarette pack-years was 32.83 \pm 18.19 .

\section{Construct validity}

According to the results of the seven-factor model in the original version of the WSWS, the CFA was performed to examine the suitability of the seven-factor structure 


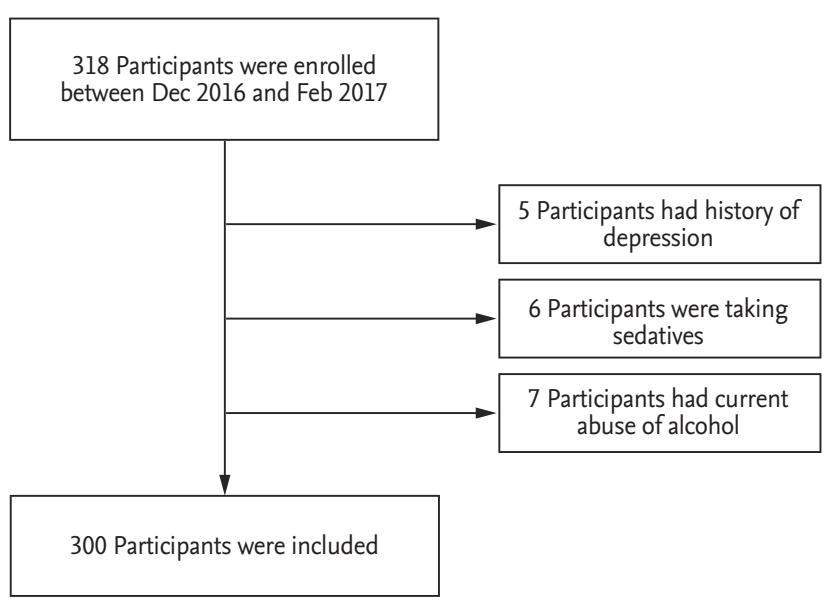

Figure 1. Flow diagram of the study.

Table 1. Baseline characteristics of the participants $(n=30)$

\begin{tabular}{lc}
\hline Variable & Value \\
\hline Sex & \\
Male & $281(93.67)$ \\
Female & $19(6.33)$ \\
Age, yr & $59.23 \pm 15.19$ \\
Height, cm & $166.62 \pm 7.67$ \\
Weight, kg & $66.75 \pm 13.70$ \\
Pack-years of smoking & $32.83 \pm 18.19$ \\
Current smoker & $254(84.7)$ \\
Ex-smoker & $46(15.3)$ \\
Comorbidity & \\
No & $98(32.67)$ \\
Yes & $202(67.33)$ \\
\hline
\end{tabular}

Values are presented as number (\%) or mean \pm SD.

${ }^{\mathrm{a} C o m o r b i d i t y ~ i n c l u d e s ~ h y p e r t e n s i o n, ~ d i a b e t e s ~ m e l l i t u s, ~ t h y-~}$ roid disease, and dyslipidemia.

of the WSWS. Additionally, MIMIC CFA was performed with the seven-factor model, which was found to be more appropriate than the one-factor model. The fit indices obtained in the CFA and MIMIC CFA are shown in Table 2. The CFA of the seven-factor structure resulted in a GFI of 0.917 , AGFI of 0.891 , CFI of 0.849 , NFI of 0.808 , and RMSEA of 0.098 . The MIMIC CFA resulted in a GFI of 0.905 , AGFI of 0.082 , CFI of 0.843 , NFI of 0.788 , and RMSEA of 0.086 . As the age increased, the WSWS score decreased and was statistically significant. Other variables were not statistically significant. The results of the CFA were generally better than those of the MIMIC CFA. However, the GFI of the MIMIC CFA was also greater than 0.9 and the RMSEA was less than 0.1. The CFA model is shown in Fig. 2. A standard coefficient estimation demonstrates statistical significance at the level of 0.05 .

\section{Distribution and correlation}

Table 3 shows the distributions of the subscale scores of the 28-item WSWS-K and the correlations among the scores of the subscales of the WSWS-K. Overall, the subscales were positively correlated with each other. Anxiety was strongly positively correlated with anger, sadness, and concentration $(r=0.749, r=0.726$, and $r=0.636$, respectively), and sadness was strongly positively correlated with anger $(r=0.654)$. Some correlation coefficients were negative and statistically significant. Hunger was negatively correlated with sleep $(r=-0.257)$. Some correlation coefficients were statistically significant (less than 0.01 ), but the effects size were all less than $0.250: r=$ 0.231 (craving, anxiety), $r=0.238$ (craving, concentration), $r=0.170$ (craving, sadness), $r=0.201$ (sleep, anxiety), and $r=0.218$ (sleep, concentration).

\section{Criterion-related validity}

Criterion-related validity was assessed by examining the relationships of the subscale scores of the WSWS-K with the matched items of the MNWS-K. The total score of the WSWS-K was statistically significantly positively correlated with the MNWS-K questionnaire's total score (0.768; $p<0.01$ ) (Table 4). Additionally, the subscales of the WSWS-K were statistically significantly positively correlated with the matched items of the MNWS-K. Thus, the WSWS-K was highly correlated with the MNWS-K, and the WSWS-K is sufficiently valid to measure smoking withdrawal symptoms among Koreans (the Pearson's product moment correlation was 0.768 , indicating a strong linear correlation). A simple linear regression was performed to examine the predictive validity of the two questionnaires. A good correlation was found between the total scores of the WSWS-K and MNWS-K (Fig. 3). Additionally, we performed linear regression between the WSWS-K and MNWS-K with adjustment of age, gender, comorbidity, and smoking history. After adjustment for these variables, the WSWS-K was 
Table 2. Confirmatory factor analysis and multiple indicators and multiple causes confirmatory factor analysis of the Korean version of the Wisconsin Smoking Withdrawal Scale

\begin{tabular}{|c|c|c|c|}
\hline Factor analyses & CFA (seven-factor) & CFA (one-factor) & MIMIC CFA (seven-factor) \\
\hline \multicolumn{4}{|l|}{ Variable } \\
\hline Male sex & - & - & -0.404 \\
\hline Age & - & - & $-0.013^{\mathrm{a}}$ \\
\hline Comorbidity & - & - & 0.112 \\
\hline Smoking & - & - & 0.006 \\
\hline \multicolumn{4}{|c|}{ Goodness of fit indices } \\
\hline $\mathrm{df}$ & 329 & 350 & 451 \\
\hline Chi-square & $1,275.12$ & $4,433.03$ & $1,438.13$ \\
\hline$p$ value & $<0.001$ & $<0.001$ & $<0.001$ \\
\hline GFI & 0.917 & 0.824 & 0.905 \\
\hline AGFI & 0.891 & 0.782 & 0.882 \\
\hline CFI & 0.849 & 0.347 & 0.843 \\
\hline NFI & 0.808 & 0.331 & 0.788 \\
\hline RMR & 0.095 & 0.201 & 0.588 \\
\hline RMSEA & 0.098 & 0.197 & 0.086 \\
\hline
\end{tabular}

CFA, confirmatory factory analysis; MIMIC, multiple indicators and multiple causes; df, degree of freedom; GFI, goodnessof-fit index; AGFI, adjusted goodness-of-fit index; CFI, comparative fit index; NFI, normed fit index; RMR, root mean square residual; RMSEA, root mean square error of approximation.

a $p<0.05$.

also statistically significantly positively correlated with the MNWS-K. The results are shown in Table 5.

\section{Internal consistency reliability}

As a result of the internal consistency of the scales, Cronbach's alpha of the overall scale was 0.87 (above the pre-specified criterion of 0.70 ), thus reflecting good internal consistency reliability [21]. Cronbach's alpha of the seven subscales ranged from 0.68 to 0.95 . Generally, Cronbach's alpha exceeded 0.70; it was below 0.70 (0.68) only for concentration. Although, the value for concentration was lower than that for the other variables, the overall Cronbach's alpha value demonstrated competent reliability. The Cronbach's alpha coefficients for the WSWS-K are summarized in Table 6.

\section{DISCUSSION}

To our knowledge, this is the first report on the translation and validation of the WSWS in the Korean language.
Previous studies of interval consistency reliability of the seven subscales of the original version of the WSWS had reported values of Cronbach's alpha of 0.91 (range, 0.75 to 0.93 ) [11] and 0.91 (range, 0.76 to 0.91 ) [10]. In this study, Cronbach's alpha coefficient was 0.87 (range, o.68 to 0.95). As Cronbach's alpha coefficients for the overall instrument were shown to be relatively high and above the standard of 0.70 , the WSWS-K was considered to be reliable. The value for concentration was relatively lower than that for the other variables. This difference could be explained by the fact that, compared to a previous validation study, this study had many older participants. The average age of the participants in this study was 59.23 years, and the study included 95 people over the age of 70 years. This demographic may have influenced the results of the survey because concentration decreases with age $[22,23]$. We conducted CFA to assess construct validity. In this study, the AGFI of the seven-factor model was 0.891 and RMSEA was 0.098 . In a previous study, Etter and Hughes [10] examined validity by comparing the WSWS and the MNWS. They performed CFA of the 
Figure 2. Path diagram of a confirmatory factor analysis of the Korean version of Wisconsin smoking withdrawal scale. ${ }^{a} p<0.01$.

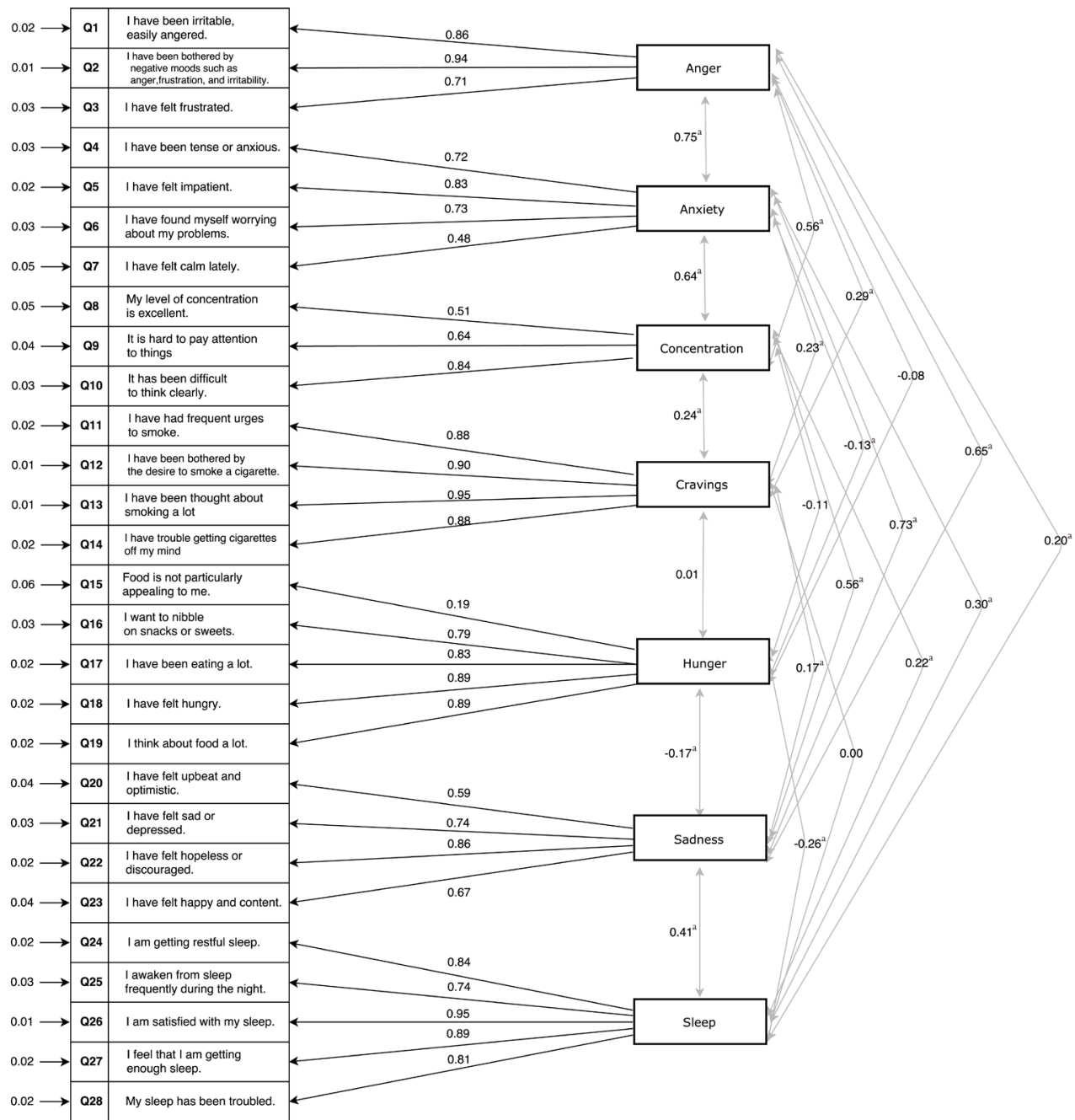

Table 3. Distributions of subscale scores and Pearson's correlation coefficients among 28 -items of Korean version of the Wisconsin Smoking Withdrawal Scale $(\mathbf{n}=300)$

\begin{tabular}{|c|c|c|c|c|c|c|c|c|c|}
\hline \multirow{2}{*}{ Subscale } & \multirow{2}{*}{ Mean \pm SD } & \multirow{2}{*}{ Median (min-max) } & \multicolumn{7}{|c|}{ Correlation coefficients } \\
\hline & & & 1 & 2 & 3 & 4 & 5 & 6 & 7 \\
\hline 1. Anger & $3.10 \pm 3.14$ & $3.00(0-11)$ & - & & & & & & \\
\hline 2. Anxiety & $5.13 \pm 3.65$ & $5.00(0-16)$ & $0.749^{b}$ & - & & & & & \\
\hline 3. Concentration & $4.27 \pm 2.74$ & $4.00(0-12)$ & $0.557^{\mathrm{b}}$ & $0.636^{\mathrm{b}}$ & - & & & & \\
\hline 4. Craving & $10.51 \pm 3.77$ & $12.00(0-16)$ & $0.289^{b}$ & $0.231^{b}$ & $0.238^{b}$ & - & & & \\
\hline 5. Hunger & $11.47 \pm 4.10$ & $12.00(0-20)$ & -0.079 & $-0.126^{\mathrm{a}}$ & -0.111 & 0.011 & - & & \\
\hline 6. Sadness & $4.46 \pm 2.92$ & $3.50(0-14)$ & $0.654^{b}$ & $0.726^{b}$ & $0.557^{\mathrm{b}}$ & $0.170^{b}$ & $-0.166^{b}$ & - & \\
\hline 7. Sleep & $6.78 \pm 4.84$ & $4.00(0-20)$ & $0.201^{b}$ & $0.296^{\mathrm{b}}$ & $0.218^{b}$ & -0.003 & $-0.257^{b}$ & $0.409^{b}$ & - \\
\hline 8. Whole score & $45.71 \pm 14.25$ & $43.00(15-90)$ & $0.775^{\mathrm{b}}$ & $0.817^{b}$ & $0.697^{b}$ & $0.470^{b}$ & 0.099 & $0.778^{b}$ & $0.511^{b}$ \\
\hline
\end{tabular}

a $p<0.05$.

$\mathrm{b} p<0.01$. 
original version of WSWS and AGFI was 0.87 [10], which falls below 0.90 . Hence, the AGFI value obtained in the current study was above the value in the original study [10], and it would be appropriate to conclude that the

Table 4. Validity of items on the Korean version of the Wisconsin Smoking Withdrawal Scale $(\mathbf{n}=300)$

\begin{tabular}{lc}
\hline Wisconsin & Minnesota \\
\hline Anger & $0.78^{\mathrm{a}}$ \\
Anxiety & $0.672^{\mathrm{a}}$ \\
Concentration & $0.621^{\mathrm{a}}$ \\
Cravings & $0.820^{\mathrm{a}}$ \\
Hunger & $0.741^{\mathrm{a}}$ \\
Sadness & $0.657^{\mathrm{a}}$ \\
Sleep & $0.797^{\mathrm{a}}$ \\
Whole score & $0.768^{\mathrm{a}}$ \\
\hline
\end{tabular}

${ }^{a} p<0.01$.

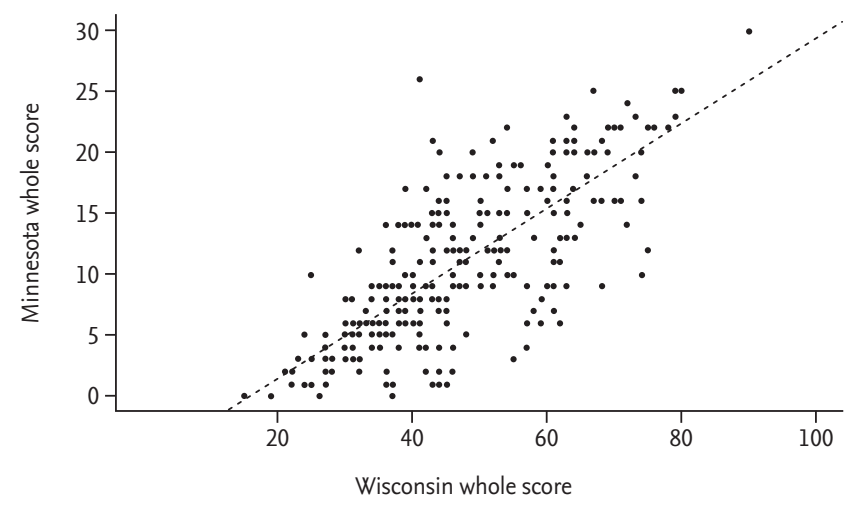

Figure 3. Regression plot of the Wisconsin questionnaire total score versus Minnesota questionnaire total score $(\beta=0.35$, $\left.p<0.001, R^{2}=0.59\right)$. structure of the questionnaire has been adequately designed. These results indicated that the WSWS-K was psychometrically sound and appropriate for evaluating nicotine withdrawal symptoms among Koreans.

Hughes and Hatsukami [9] developed the MNWS in 1986, and the scale was modified to reflect changes made in the DSM-IV criteria for nicotine withdrawal in 1996 [24]. The MNWS includes eight items (depressed mood [sad], insomnia, irritable/frustrated/angry, anxious [nervous], difficulty concentrating, restless [impatient], increased appetite, and desire or craving to smoke) answered on 5-point Likert-type scales raging from 'none' to 'severe.' It is the briefest scale available among the self-report measures of nicotine withdrawal currently used, and its psychometric properties have been reported to be as good as those for other, longer questionnaires (Cronbach's alpha was 0.85 , and the test-retest intraclass correlation coefficient over a 14-day period was 0.71). Thus, we decided to assess the criterion-related validity by examining the relationship of the subscales of the WSWS-K with matched items on the MNWS-K. Seven of eight items on the MNWS-K, except 'restless,' were matched to each other. The total score and the subscales of the WSWS-K were highly correlated with the MNWS-K, and the correlation analysis demonstrated that the WSWS-K has good validity to measure nicotine withdrawal symptoms.

Continuous and accurate assessment of nicotine dependence and withdrawal symptoms is required for effective smoking cessation and smokers' education. The Fagerström Test for Nicotine Dependence (FTND) [25] is the most commonly used measure of nicotine dependence. However, it only measures physiological dependence, and has limitations that it cannot measure psychological dependence such as craving. The Mood and

Table 5. Linear regression between the MNWS-K and the WSWS-K with adjustment of age, sex, comorbidity, and smoking

\begin{tabular}{lcccc}
\hline Variable & $\beta$ & SE & \multicolumn{1}{c}{$t$ value } & $p$ value \\
\hline Intercept & -6.07 & 1.62 & -3.74 & 0.0002 \\
WSWS-K & 0.35 & 0.02 & 20.76 & 0.001 \\
Age & 0.01 & 0.02 & 0.59 & 0.5538 \\
Sex, male (ref) vs. female & -0.22 & 1.04 & -0.21 & 0.8319 \\
Comorbidity, no (ref) vs. yes & 0.43 & 0.56 & 0.77 & 0.4415 \\
Smoking & -0.01 & 0.02 & -0.63 & 0.5310 \\
\hline
\end{tabular}

MNWS-K, Korean version of the Minnesota Nicotine Withdrawal Scale; WSWS-K, Korean version of the Wisconsin Smoking Withdrawal Scale; SE, standard error. 
Table 6. Cronbach's alpha coefficient for items on the Korean version of the Wisconsin Smoking Withdrawal Scale $(n=300)$

\begin{tabular}{lc}
\hline Subscale & Cronbach's alpha \\
\hline Anger & 0.86 \\
Anxiety & 0.77 \\
Concentration & 0.68 \\
Cravings & 0.95 \\
Hunger & 0.83 \\
Sadness & 0.80 \\
Sleep & 0.93 \\
Whole scale & 0.87 \\
\hline
\end{tabular}

Physical Symptoms Scale (MPSS) [26] and MNWS have been widely used to measure withdrawal symptoms. However, both the MPSS and MNWS have the disadvantage that one withdrawal symptom is measured with on single item. Because the WSWS measures one withdrawal symptom with several items, it is able to measure withdrawal symptoms more accurately [10]. In this study, we developed the Korean version of the WSWS and its validity and reliability were confirmed in Korean smokers.

Our study has several limitations. First, the majority of participants (93.7\%) in this study were male. However, from the Korean statics in 2016, the smoking rate was $39.1 \%$ and $3.1 \%$ in adult men and women, respectively [27]. More specifically, the smoking rates of men in fifties, sixties and seventies were $36.3 \%, 25.3 \%$, and $15.5 \%$, respectively. In contrast, the smoking rates of women in fifties, sixties and seventies were $2.9 \%, 1.9 \%$, and $1.1 \%$, respectively [28]. Overall, the smoking rate of women in Korea is very low, particularly at the age of 50 to70 years, which is reflective of the subjects in this study. In this respect, the number of women in this study was not very small. Second, the participants comprise current smokers and former smokers had stopped smoking within the last year. Therefore, there may be a difference in severity of the withdrawal symptoms. However, from the previous study [29], withdrawal symptoms can be last until 1 year after smoking cessation and significant craving symptom disappear after 1 year. Third, the participants were a convenient sample recruited exclusively from outpatients visiting our hospital, which means that no evaluation was made for smokers who do not visit the hospital. Fourth, the lack of sociodemographic information limits the ability to generalize the results. Finally, because the study utilized self-reported measures of nicotine withdrawal symptoms, there was no way of determining whether these symptoms were overreported or underreported.

Considering the appropriate psychometric evidentiary properties provided by our study, we conclude that the WSWS-K is an appropriate, reliable, and valid instrument for assessing nicotine withdrawal symptoms including cravings, among Korean smokers. In Korea, the national reimbursement program for medical costs of smoking cessation was launched in 2015. If a smoker succeeds in quitting smoking, all medical costs related to smoking cessation are supported by the Korean government. The smoking cessation program only evaluates the dependence of nicotine using the FTND [25] at the initiation of treatment, and there are no Korean language tools available to assess nicotine withdrawal symptoms that can occur during treatment. The WSWS-K can be used to evaluate the withdrawal symptoms in smokers who joined the reimbursement program for medical costs of smoking cessation. Additionally, the WSWS-K can be used in future research and clinical evaluations of Korean smokers with acceptable validity and reliability.

\section{KEY MESSAGE}

1. The original version of the Wisconsin Smoking Withdrawal Scale was translated into the Korean language.

2. The Korean version of the Wisconsin Smoking Withdrawal Scale (WSWS-K) was validated in smokers.

3. Satisfactory internal consistency coefficients together with the validity findings suggest the use of the WSWS-K in the Korean population.

\section{Conflict of interest}

No potential conflict of interest relevant to this article was reported.

\section{Acknowledgments}

The authors would like to thank Minyoung Park (The Korea Herald, Seoul, Korea) and Jennifer Cramer (USA) 
for back translation and Sun Hee Gang (St. Paul's Hospital, Seoul, Korea) for assistance in data collection.

\section{REFERENCES}

1. United States Public Health Service Office of the Surgeon General; United States Department of Health and Human Services. The Health Consequences of Smoking-50 Years of Progress: A Report of the Surgeon General. Atlanta (GA): U.S. Department of Health and Human Services, 2014 .

2. Jamal A, King BA, Neff LJ, Whitmill J, Babb SD, Graffunder CM. Current cigarette smoking among adults: United States, 2005-2015. MMWR Morb Mortal Wkly Rep 2016;65:1205-1211.

3. Ministry of Health and Welfare, Korea Centers for Disease Control and Prevention. Korea Health Statistics 2015: Korea National Health and Nutrition Examination Survey (KNHANES VI-3). Sejong (KR): Ministry of Health and Welfare, 2016.

4. Jha $\mathrm{P}$, Ramasundarahettige $\mathrm{C}$, Landsman V, et al. 21st-century hazards of smoking and benefits of cessation in the United States. N Engl J Med 2013;368:341-50.

5. Cao Y, Kenfield S, Song Y, et al. Cigarette smoking cessation and total and cause-specific mortality: a 22-year follow-up study among US male physicians. Arch Intern Med 2011;171:1956-1959.

6. Henningfield JE, Keenan RM. Nicotine delivery kinetics and abuse liability. J Consult Clin Psychol 1993;61:743-750.

7. Hatsukami DK, Stead LF, Gupta PC. Tobacco addiction. Lancet 2008;371:2027-2038.

8. Benowitz NL. Nicotine addiction. Prim Care 1999;26:611631.

9. Hughes JR, Hatsukami D. Signs and symptoms of tobacco withdrawal. Arch Gen Psychiatry 1986;43:289-294.

10. Etter JF, Hughes JR. A comparison of the psychometric properties of three cigarette withdrawal scales. Addiction 2006;101:362-372.

11. Welsch SK, Smith SS, Wetter DW, Jorenby DE, Fiore MC, Baker TB. Development and validation of the Wisconsin Smoking Withdrawal Scale. Exp Clin Psychopharmacol 1999;7:354-361.

12. West R, Ussher M, Evans M, Rashid M. Assessing DSM-IV nicotine withdrawal symptoms: a comparison and evaluation of five different scales. Psychopharmacology (Berl)
2006;184:619-627.

13. Kim SS, Gulick EE, Kim SH, Seo HG. Psychometric properties of the Minnesota Nicotine Withdrawal Scale: a Korean version. J Nurs Meas 2007;15:121-132.

14. Flaherty JA, Gaviria FM, Pathak D, et al. Developing instruments for cross-cultural psychiatric research. J Nerv Ment Dis 1988;176:257-263.

15. Behling O, Law KS. Translating Questionnaires and Other Research Instruments: Problems and Solutions. Thousand Oaks (CA): Sage Publications, 2000.

16. Streiner DL, Norman GR. Health Measurement Scales: A Practical Guide to Their Development and Use. 3rd ed. Toronto (ON): Oxford University, 2003.

17. Hair JF Jr, Black WC, Babin BJ, Anderson RE. Multivariate Data Analysis. 7 th ed. Upper Saddle River (NJ): Pearson Prentice Hall, 2010.

18. Browne MW, Cudeck R. Alternative ways of assessing model fit. Sociol Methods Res 1992;21:230-258.

19. Meyers LS, Gamst G, Guarino AJ. Applied Multivariate Research: Design and Interpretation. Thousand Oaks (CA): SAGE Publications, 2006.

20. Rao CR, Miller JP, Rao DC. Handbook of Statistics 27: Epidemiology and Medical Statistics. Amsterdam (NL): Elsevier, 2008.

21. DeVellis RF. Scale Development: Theory and Applications. Thousand Oaks (CA): Sage Publications, 2003.

22. Ferrucci L, Studenski S. Clinical problems of aging. In: Kasper DL, Fauci AS, Hauser S, Longo DL, Jameson JL, Loscalzo J, ed. Harrison's Principles of Internal Medicine. 19th ed. New York (NY): McGraw-Hill Medical, 2014.

23. Organic mental impairment in the elderly. Implications for research, education and the provision of services. A report of the Royal College of Physicians by the College Committee on Geriatrics. J R Coll Physicians Lond 1981;15:141-167.

24. Jorenby DE, Hatsukami DK, Smith SS, et al. Characterization of tobacco withdrawal symptoms: transdermal nicotine reduces hunger and weight gain. Psychopharmacology (Berl) 1996;128:130-138.

25. Fagerstrom KO. Measuring degree of physical dependence to tobacco smoking with reference to individualization of treatment. Addict Behav 1978;3:235-241.

26. Hajek P. Withdrawal-oriented therapy for smokers. Br J Addict 1989;84:591-598.

27. National Health Insurance Service. 2016 National health screening statistical yearbook [Internet]. Wonju (KR): 
National Health Insurance Service, c2017 [cited 2019 Nov 26]. Available from: http://www.nhis.or.kr/bbs7/boards/ Bo159/24874.

28. Korean Statistical Information Service. Smoking rate statistics [Internet]. Daejeon (KR): KOSIS, c2017 [cited 2019 Nov 26]. Available from: http://kosis.kr/statHtml/
statHtml.do?orgId=101\&tblId=DT_2KAACo $4 \&$ conn_ path=I2.

29. Schlam TR, Piper ME, Cook JW, Fiore MC, Baker TB. Life 1 year after a quit attempt: real-time reports of quitters and continuing smokers. Ann Behav Med 2012;44:309-319. 


\section{Supplementary Table 1. Comparison of the 28 -item Wisconsin Smoking Withdrawal Scale sorted by subscale between the original and the Korean version}

\begin{tabular}{|c|c|c|c|}
\hline The original version & The Korean version & Subscale & $\begin{array}{c}\text { The Korean } \\
\text { version }\end{array}$ \\
\hline 13. I have been irritable, easily angered. & 13. 나는 짜증이 나고, 쉽게 화가 난다. & Anger & 분노 \\
\hline $\begin{array}{l}\text { 15. I have been bothered by negative moods such } \\
\text { as anger, frustration, and irritability. }\end{array}$ & $\begin{array}{l}\text { 15. 나는 화, 우울, 짜증 등의 부정적인 감정 } \\
\text { 때문에 괴롭다. }\end{array}$ & & \\
\hline 18. I have felt frustrated. & 18. 나는 좌절감을 느낀다. & & \\
\hline 3. I have been tense or anxious. & 3. 나는 긴장되거나 불안하다. & Anxiety & 불안 \\
\hline 6. I have felt impatient. & 6. 나는 참을성이 없다. & & \\
\hline 8. I have found myself worrying about my problems. & 8. 나는 내 문제에 대해 걱정이 많다. & & \\
\hline 10. I have felt calm lately. ${ }^{\text {a }}$ & 10. 나는 최근 침착하다. ${ }^{\mathrm{a}}$ & & \\
\hline 4. My level of concentration is excellent. ${ }^{a}$ & 4. 나의 집중력은 우수하다. ${ }^{\mathrm{a}}$ & Concentration & 주의집중 \\
\hline 23. It is hard to pay attention to things. & 23. 나는 집중하기 어렵다. & & \\
\hline 27. It has been difficult to think clearly & 27. 나는 명확하게 생각하는 것이 힘이 든다. & & \\
\hline 9. I have had frequent urges to smoke. & 9. 나는 자주 담배 충동을 느끼곤 한다. & Craving & 갈망 \\
\hline $\begin{array}{l}\text { 11. I have been bothered by the desire to smoke } \\
\text { a cigarette. }\end{array}$ & $\begin{array}{l}\text { 11. 나는 담배를 피우고 싶은 마음 때문에 } \\
\text { 성가시다. }\end{array}$ & & \\
\hline 20. I have thought about smoking a lot. & 20. 나는 담배에 대해 자주 생각한다. & & \\
\hline 26. I have trouble getting cigarettes off my mind. & $\begin{array}{l}\text { 26. 나는 담배에 대한 생각을 떨쳐내기가 } \\
\text { 힘들다. }\end{array}$ & & \\
\hline 1. Food is not particularly appealing to me. ${ }^{\mathrm{a}}$ & 1. 나는 입맛이 없다. ${ }^{a}$ & Hunger & 공복 \\
\hline 14. I want to nibble on snacks or sweets. & 14. 나는 과자나 군것질거리를 먹고 싶다. & & \\
\hline 16. I have been eating a lot. & 16. 나는 최근 많이 먹는다. & & \\
\hline 21. I have felt hungry. & 21. 나는 배고픔을 느낀다. & & \\
\hline 28. I think about food a lot. & 28. 나는 음식에 대한 생각을 자주 한다. & & \\
\hline 7. I have felt upbeat and optimistic.a & 7. 나는 긍정적이고 낙관적이다. ${ }^{\mathrm{a}}$ & Sadness & 우울 \\
\hline 12. I have felt sad or depressed. & 12. 나는 슬프거나 우울하다. & & \\
\hline 19. I have felt hopeless or discouraged. & $\begin{array}{l}\text { 19. 나는 낙담하거나 희망이 없는 것처럼 } \\
\text { 느낀다. }\end{array}$ & & \\
\hline 24. I have felt happy and content. ${ }^{\text {a }}$ & 24. 나는 행복하고 만족한다. ${ }^{\mathrm{a}}$ & & \\
\hline 2. I am getting restful sleep. ${ }^{a}$ & 2. 나는 편안한 숙면을 취한다. ${ }^{a}$ & Sleep & 수면 \\
\hline 5. I awaken from sleep frequently during the night. & 5. 나는 밤에 자다가 자주 깬다. & & \\
\hline 17. I am satisfied with my sleep. ${ }^{\text {a }}$ & 17. 나는 나의 수면에 만족한다. ${ }^{\mathrm{a}}$ & & \\
\hline 22. I feel that I am getting enough sleep. ${ }^{a}$ & $\begin{array}{l}\text { 22. 나는 충분한 양의 수면을 취한다고 } \\
\text { 생각한다. }{ }^{a}\end{array}$ & & \\
\hline 25. My sleep has been troubled. & 25. 나는 수면을 잘 취하지 못한다. & & \\
\hline
\end{tabular}

${ }^{a}$ These items are reverse scored. 


\section{KJIM}

Supplementary Table 2. The Korean version of the Wisconsin Smoking Withdrawal Scale(WSWS-K) (한국어판 위스콘신 금단 증상 척도)

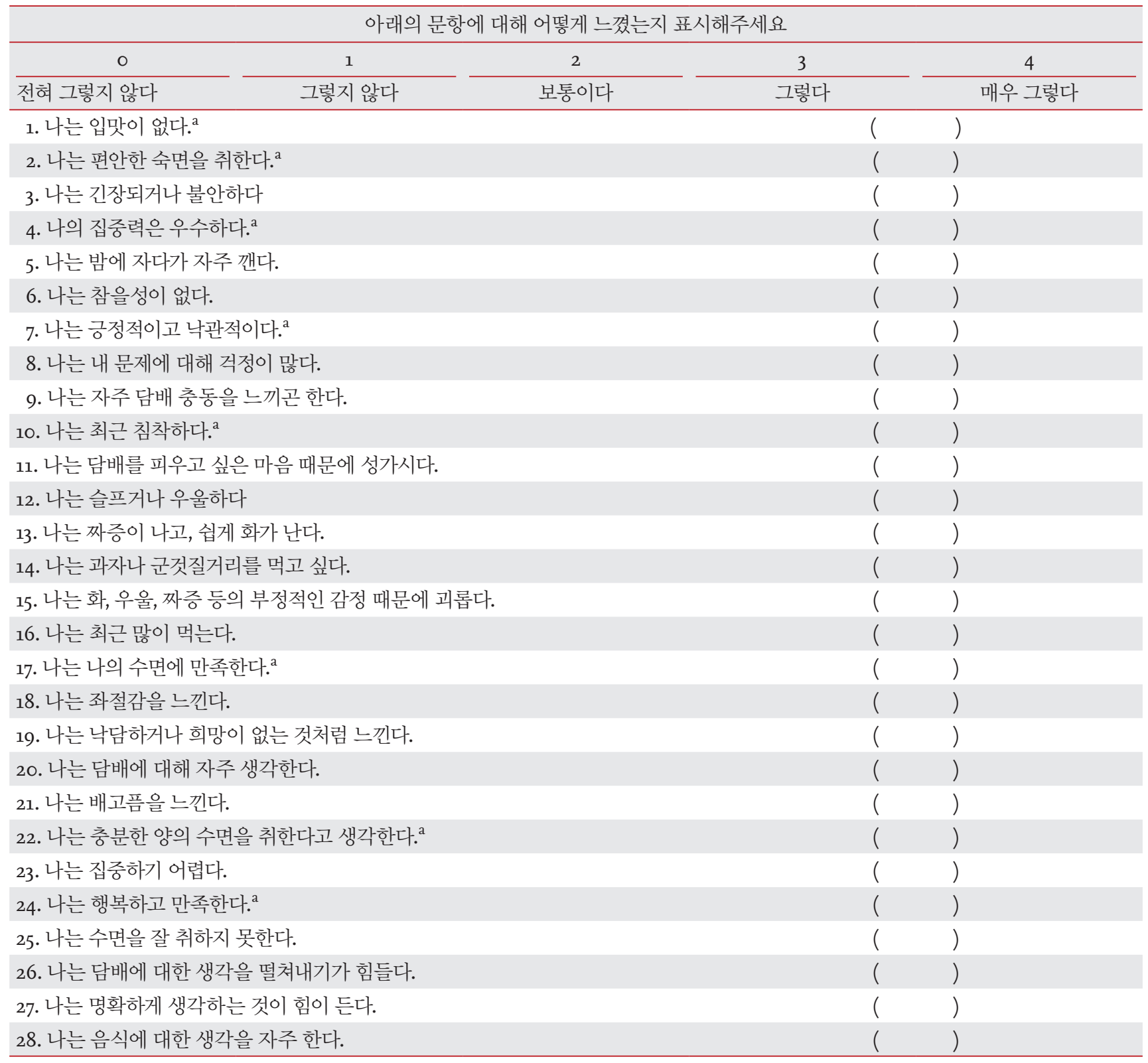

a역산문항. 